1 School of Medicine, Keele University, Keele, UK

2 Public Health, Policy, and Systems, Institute of Population Health Sciences, University of Liverpool, Liverpool, UK

3 NHS Birmingham and Solihull Clinical Commissioning Group, Birmingham, UK

4 Royal College of General Practitioners Midland Faculty, Birmingham, UK

Correspondence to: F Mughal

f.mughal@keele.ac.uk

Cite this as: BMJ2021;373:n1064

http://dx.doi.org/10.1136/bmj.n1064

Published: 04 May 2021

\section{Mental health support through primary care during and after covid-19}

\author{
Faraz Mughal, ${ }^{1}$ Muhammad Z Hossain, ${ }^{2}$ Angela Brady, ${ }^{3}$ Judy Samuel, ${ }^{4}$ Carolyn A Chew-Graham
}

The recent surge in cases of covid-19 in the UK has deepened concern over the pandemic's possible mental health consequences. ${ }^{12}$

Covid-19 has raised the prevalence of anxiety, depression, post-traumatic stress disorder, and psychological and mental distress among the general population. ${ }^{134}$ Living with young children, pre-existing chronic or mental illness, young age, female gender, and frequent exposure to pandemic news are all risk factors associated with covid-19 related distress. ${ }^{34}$ Rates of suicidal thoughts increased in people aged 18-29 during the pandemic, highlighting the particular toll of covid-19 on young people. $^{5}$

Repeated episodes of lockdown, periods of self-isolation after contact with infected people, social distancing, and the fear of contracting covid-19 when outside the home can lead to heightened fear and anxiety in people of all ages. Self-isolation is associated with symptoms of post-traumatic stress, anxiety, adjustment disorder, confusion, and anger. ${ }^{67}$

The implications of covid-19 for people with pre-existing mental illness are of particular concern, along with the likelihood that covid-19 will further widen mental health inequalities for ethnic minority groups.

Against this backdrop, mental health support through primary care is a priority for patients, the public, commissioners, researchers, and policy makers.

Around $90 \%$ of mental health problems are managed entirely in primary care, and general practitioners report that mental health constitutes around $40 \%$ of their workload. ${ }^{8} 9$ The World Health Organization suggests that good primary care management of people with mental health problems reduces stigma and improves access to treatment. ${ }^{10}$ Early intervention in primary care has been shown to reduce subsequent mental health problems and be cost effective. ${ }^{1112}$

Covid-19 has changed general practice at scale, including the near universal implementation of remote consulting, which is new to many primary care teams in the UK. ${ }^{13}$ Primary care is now at the forefront of the predicted increase in mental health presentations: covid-19 is thought to have affected or be likely to affect the mental health of around 10 million people through lockdown restrictions; concerns about employment, finances, personal safety, or the safety of family members; and bereavement. ${ }^{14} 15$ The wellbeing of children and young people has been further undermined by educational disruption and isolation from peers.

Patients with long covid describe the fear, uncertainty, and despair caused by persistent symptoms and emphasise mental health support as a key part of recovery. ${ }^{16}$ People with active covid-19 are worried about their prognosis, while those admitted to intensive care-and their families and carers-experience substantial mental health distress. These are all risk factors for subsequent mental illness.

Rates of self-harm and common mental health conditions were lower than expected in primary care during the early stages of the pandemic, but concern remains about a possible rebound effect causing higher rates of mental health problems, self-harm, and suicide in the coming months and years. ${ }^{17}$

\section{Future priorities}

Primary care needs urgent and sustained mental health investment to provide early identification of mental health conditions, timely intervention and treatment, prevention, ongoing support, and access to specialist mental healthcare services. This should be a priority for the integrated care systems at the heart of NHS restructuring proposals. ${ }^{18}$

Increased capacity and enhanced access to psychological therapies in primary care is essential for all age groups (for example, through the improving access to psychological therapies programme) along with increased support for grassroots community initiatives. ${ }^{19}$

Remote primary care consultations for mental health have not been evaluated in the UK, and the loss of in-person interaction between clinician and patient may undermine the rapport essential for effective mental healthcare. Remote consultation may also reduce a clinician's ability to identify important cues, including the possibility of substance misuse, domestic violence, self-harm, grief, low mood, signs of psychosis, or anxiety, particularly in young people, parents, and carers. Primary care professionals must have the time and resources required to support patients to self-care, in line with recent guidance by the Royal College of General Practitioners. ${ }^{20}$

Research to identify best practice for remote mental health consultations in primary care is urgently required, including studies exploring both enablers and barriers to accessing remote mental health support. Changes to services must not be allowed to widen health inequalities further, through digital exclusion, for example. How to provide safe and effective care for people without stable access to digital devices should be a research priority.

We must refocus, rebuild, and revitalise mental health support through primary care to aid the recovery from covid-19, to streamline health services, promote positive mental health, and be ready for future uncertainties.

Competing interests: The BM/has judged that there are no disqualifying financial ties to commercial companies. The authors declare the following other interests: 
$\mathrm{FM}, \mathrm{AB}$, and $\mathrm{CAC}-\mathrm{G}$ are general practitioners. The $B M$ / policy on financial interests is here: https://www.bmj.com/sites/default/files/attachments/resources/2016/03/16-current-bmj-educationcoi-form.pdf. The views expressed are those of the authors not necessarily those of their funders or employers.

Provenance and peer review: Not commissioned; externally peer reviewed.

1 Jia R, Ayling K, Chalder T, etal. Mental health in the UK during the COVID-19 pandemic: cross-sectional analyses from a community cohort study. BMJ Open 2020;10:e040620. doi: 10.1136/bmjopen-2020-040620 pmid: 32933965

2 Moreno C, Wykes T, Galderisi S, etal. How mental health care should change as a consequence of the COVID-19 pandemic. Lancet Psychiatry 2020;7:813-24. doi: 10.1016/S2215-0366(20)30307-2 pmid: 32682460

3 Xiong J, Lipsitz O, Nasri F, etal. Impact of COVID-19 pandemic on mental health in the general population: A systematic review. J Affect Disord 2020;277:55-64. doi: 10.1016/j.jad.2020.08.001 pmid: 32799105

4 Pierce M, Hope H, Ford T, etal. Mental health before and during the COVID-19 pandemic: a longitudinal probability sample survey of the UK population. Lancet Psychiatry 2020;7:883-92. doi: 10.1016/S2215-0366(20)30308-4 pmid: 32707037

5 O'Connor RC, Wetherall K, Cleare S, etal. Mental health and well-being during the COVID-19 pandemic: longitudinal analyses of adults in the UK COVID-19 Mental Health \& Wellbeing study. Br J Psychiatry 2020:1-8. doi: 10.1192/bjp.2020.212 pmid: 33081860

6 Rossi R, Socci V, Talevi D, etal. Covid-19 pandemic and lockdown measures impact on mental health among the general population in Italy. Front Psychiatry 2020;11:790. doi: 10.3389/fpsyt.2020.00790 pmid: 32848952

7 Brooks SK, Webster RK, Smith LE, etal. The psychological impact of quarantine and how to reduce it: rapid review of the evidence. Lancet 2020;395:912-20. doi: 10.1016/S0140-6736(20)30460-8 pmid: 32112714

8 Royal College of General Practitioners. 90 per cent of people with mental health problems cared for within primary care. 2017. https://www.rcgp.org.uk/clinical-and-research/about/clinicalnews/2017/december/90-per-cent-of-people-with-mental-health-problems-cared-for-withinprimary-care.aspx]

9 Mind. 40 per cent of all GP appointments about mental health. 2018 https://www.mind.org.uk/news-campaigns/news/40-per-cent-of-all-gp-appointments-aboutmental-health/]

10 World Health Organization. Mental health in primary care. 2013. https://www.euro.who.int/en/health-topics/noncommunicable-diseases/mental-health/priority-areas/mentalhealth-in-primary-care

11 van't Veer-Tazelaar PJ, van Marwijk HW, van Oppen P, etal. Stepped-care prevention of anxiety and depression in late life: a randomized controlled trial. Arch Gen Psychiatry 2009;66:297-304. doi: 10.1001/archgenpsychiatry.2008.555 pmid: 19255379

12 van't Veer-Tazelaar P, Smit F, van Hout H, etal. Cost-effectiveness of a stepped care intervention to prevent depression and anxiety in late life: randomised trial. BrJ Psychiatry 2010;196:319-25. doi: 10.1192/bjp.bp.109.069617 pmid: 20357310

13 Gray DP, Freeman G, Johns C, Roland M. Covid 19: a fork in the road for general practice. BMJ 2020;370:m3709. doi: 10.1136/bmj.m3709 pmid: 32988832

14 Park S, Elliott J, Berlin A, Hamer-Hunt J, Haines A. Strengthening the UK primary care response to covid-19. BMJ 2020;370:m3691. doi: 10.1136/bmj.m3691 pmid: 32978177

15 Centre for Mental Health. Covid-19 and the nation's mental health: forecasting needs and risks in the UK. 2020. https://www.centreformentalhealth.org.uk/sites/default/files/publication/download/CentreforMentalHealth_COVID_MH_Forecasting3_Oct20_0.pdf

16 Kingstone T, Taylor AK, O'Donnell CA, Atherton H, Blane DN, Chew-Graham CA. Finding the "right" GP: a qualitative study of the experiences of people with long-COVID. BJGP Open 2020;4:bjgpopen20X101143. doi: 10.3399/bjgpopen20X101143 pmid: 33051223

17 Carr MJ, Steeg S, Webb RT, etal. Effects of the COVID-19 pandemic on primary care-recorded mental illness and self-harm episodes in the UK: a population-based cohort study. Lancet Public Health 2021;6:e124-35. doi: 10.1016/S2468-2667(20)30288-7 pmid: 33444560

18 Alderwick H, Dunn P, Gardner T, Mays N, Dixon J. Will a new NHS structure in England help recovery from the pandemic?BM/2021;372:n248. doi: 10.1136/bmj.n248 pmid: 33536236

19 Sidhu K. Improving access to psychological therapies: an idea that's failed to deliver. BMJ Opinion, 21 Oct 2019. https://blogs.bmj.com/bmj/2019/10/21/improving-access-to-psychological-therapiesan-idea-thats-failed-to-deliver/

20 Royal College of General Practitioners. General practice in the post covid world: challenges and opportunities for general practice. 2020. https://www.rcgp.org.uk/-/media/Files/News/2020/general-practice-post-covid-rcgp.ashx?la=en

This article is made freely available for use in accordance with BMJ's website terms and conditions for the duration of the covid-19 pandemic or until otherwise determined by BMJ. You may use, download and print the article for any lawful, non-commercial purpose (including text and data mining) provided that all copyright notices and trade marks are retained. 